\title{
A Study on the Intercultural Communicative Competence Cultivation Strategy of International Secretarial Personnel under the Background of Globalization
}

\author{
Qiuping Wang \\ Faculty of Chinese Language and Culture, Guangdong University of Foreign Studies, Guangzhou, China

\begin{abstract}
Under the background of globalization, intercultural communicative competence of international secretarial personnel is becoming more and more important. Therefore, it is necessary for colleges and universities to follow the needs of society and explore how to develop the intercultural communicative competence cultivation strategy of international secretarial personnel. This paper argues that at present, colleges and universities are obviously insufficient in the training of international secretarial personnel, and still need to be optimized from the aspects of textbooks, curriculum, second class and teacher quality so as to promote the intercultural communicative competence of international secretarial personnel.
\end{abstract}

Index Terms-international secretarial personnel, intercultural communicative competence, cultivation strategy

\section{INTRODUCTION}

Against the background of globalization, China has launched CAFTA, "One Belt and One Road" initiative and other major initiatives, which makes China's economy closely tie with the international economy. The number of domestic joint venture and sole proprietorship enterprises has surged and international exchanges have been frequent, which has provided a good opportunity for the development of international secretarial talents. Compared with ordinary secretaries, international secretaries are more professional and more characteristic and they mainly provides services for foreign-funded enterprises, foreign institutions in China and China's foreign - related organs and related enterprises and institutions. Therefore, as an international secretary, good intercultural communication skills are essential. It is an urgent problem for us to explore how to improve students' comprehensive English quality and promote the intercultural communicative competence of international secretarial talents so as to meet the needs of social development. This article will focus on the exploration of the cultivation strategy of optimizing the intercultural communicative competence of international secretarial talents.

\section{CurRent Situation OF Intercultural Communicative Competence of International Secretarial Talents}

\section{A. Theoretical Teaching}

Firstly, at present, the curriculum of the cultivation of intercultural communicative competence of international secretarial talents is not enough in the proportion of quantity and has not been fully valued, and most of them are just optional courses. In universities and colleges with secretary majors, the curriculum content mainly follows that of the 1980s, which is dominated by ancient Chinese literature, ancient Chinese, linguistics, foreign literature and so on. There are not many courses that really involve international cultural communication competence, and they are not professional compulsory courses but just mostly professional elective courses in the nature. Secondly, most teachers still stay in the traditional teaching mode, and the exam-oriented teaching still plays a main role. The teaching is dominated by "spoon-fed" model, which makes the classroom atmosphere dull and unattractive. The explanation of culture is not emphasized enough and it will affect students' ability to use language. The secretary major itself is a course that is based on practical application and highlights practical operation ability. If students mainly study theory in colleges and universities, it will inevitably affect the improvement of students' competitiveness after entering society. Finally, the intercultural communicative competence of some teachers still needs to be improved; otherwise, they will affect the students' study. In the present universities, some teachers lack practical experience, and most of them are college graduates who go straight into teaching in colleges and universities, so they have insufficient accumulation of practical experience and problems in international communication.

\section{B. Professional Practice}

The cultivation of international secretarial majors should put much emphasis on the direction of application 
orientation, in particular, the application of intercultural communicative competence must be fully practiced so as to really improve students' ability. However, at present, the cultivation of intercultural communicative competence of international secretaries is more of a tendency of theory teaching but pay less attention to practice. Such a situation will inevitably lead to students' lack of innovation in real intercultural communication process and the weak ability to solve practical problems. The problems of professional practice are mainly reflected in the following aspects:

1) There is not enough emphasis on the practical teaching of intercultural communication competence in secretarial major. At present, although colleges and universities pay more and more attention to the practice teaching of secretarial major, which is also reflected in the development of talent cultivation program, in fact, in practice, the practice teaching is still loose and the method of examination is still rigorous compared with the theoretical teaching. Most of the textbooks begin with the aid of theoretical teaching materials, which makes some students feel that practical teaching is only the accessory of theoretical teaching, so they do not pay enough attention to the participation and seriousness of practice teaching. The important reason for this problem is that schools, teachers and students do not pay enough attention to the practical teaching of secretarial major.

2) The synthesis and innovation of professional practice teaching content is not enough. At present, the professional practice of intercultural communication competence is basically carried out in the classroom according to the professional curriculum. The teacher will arrange both the theory teaching and practice teaching according to the teaching plan, and the phased practice teaching is aimed at the theoretical teaching in the preceding stage. Therefore, most of the students' professional practice is aimed at the content of a module, but this kind of professional practice lacks the summation and authenticity of the actual operation, and it is difficult for students to apply their knowledge in the face of real problems.

In addition, there is not enough novelty in the form and method of professional practice. The most common mode of professional practice is according to the traditional classroom teaching where the teacher will tell a part of it, and then the students will do part of their own operation; also, some case analysis, scenario simulation and group discussion will be added to it. In recent years, the form of professional practice has begun to pay attention to constructivism learning theory, which has raised the action-oriented teaching, task-driven teaching, project teaching and other teaching methods to meet the need of jobs. These two teaching methods actually have inherent deficiencies. In the traditional practice teaching form, students can't really put into practice because of lack of real environment, and it will be easy for students to lack initiative and enthusiasm for a long time. And the subsequent rise of the action-oriented teaching mode is particularly high requirements for teachers where it not only ask the teachers themselves to have rich experience in teaching practice, strong ability of comprehensive project development, but also ask the teachers to put a lot of time and energy into the practice teaching organizations, more than that put into the usual theoretical teaching. At the same time, it also has higher requirements for the students' own initiative and participation, so the difference of the implementation effect is large.

3) Professional practice teaching conditions are not fully guaranteed. The important reason for the lack of guarantee of teaching conditions is that the teaching funds are not guaranteed. The practice teaching in some areas is not enough, and the source is unitary. This further results in the lack of hardware and soft conditions for the professional practice of secretarial students. The hardware condition mainly refers to the practice teaching site, teaching equipment and so on. The soft condition mainly refers to the teaching staff of the practice teaching, the textbooks and so on.

4) The management of professional practice teaching is not comprehensive and rigorous enough. From the macro point of view, most colleges and universities have set up a relatively complete management rules and regulations in the management level of professional practice, but most of them are mainly for some macroscopic regulations, and lack of comprehensive quality assessment specifications, including the guidance of teacher assessment, student process assessment, staff management assessment and so on. In addition to the overall lack of assessment criteria, there are also inadequate places for teaching practice facilities, which include campus and off-campus practice sites.

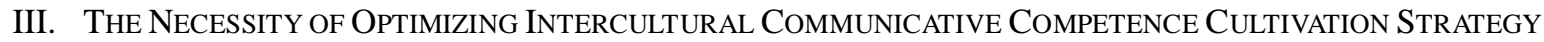

The professional characteristics of international secretarial talents determine the importance of intercultural communicative competence in their work. The following will take the two main tasks of secretarial work as the clue to analyze the importance of optimizing intercultural communicative competence cultivation strategy.

\section{A. Handling Affairs}

Secretarial work mainly includes routine reception and business activities. In these daily works, intercultural communicative competence is very important for secretaries. The language and etiquette in the process of international reception are all important factors for the secretaries to set up good public relations image and achieve the goal of public relations. In business activities, intercultural communication is also more frequent in the present. The culture of business activities varies widely because of the different objects involved. For example, In the process of business banquets, it often involves many food culture caused by cultural differences. If an international secretary lacks of understanding of these cultural differences, the failure of business banquets may be caused, thereby affecting the interests of the unit. For example, in the business activities, the two sides will inevitably offer gifts to express their hopes of mutual friendship, but different countries have different taboo of gifts and gift giving. Westerners pay more 
attention to the cultural style and artistic taste of gifts. They don't give too expensive gifts, but they attach great importance to the packaging of the gift, which means that they have a deep friendship. In addition, the religious meanings of gifts should also be put much emphasized. Almost each nation has its own religious beliefs, and if the gift made religious taboo of the other side, the relationship between the two sides will break up. At the same time, the colors of the gifts also have different connotations. For example, in Chinese and British culture, red is a very auspicious color, which represents happiness and good luck; but in Japan, red is an unlucky color, which represents danger and anger. The above fully illustrates the importance of international quality in the daily work of international secretaries, and also fully demonstrates the necessity of cultivating intercultural communicative competence for international secretary talents.

\section{B. Holding Meetings}

Meeting is an important form of activities for enterprises and institutions, and it is also an important part of secretarial work. In enterprises and institutions, the form of meetings that the secretary needs to prepare is also varied, including business negotiation meetings, internal meetings, fairs and so on. With the development of globalization, intercultural factors have become more and more enriched in various forms of meetings, which also puts forward higher requirements for intercultural communicative competence of international secretaries. Taking the seating arrangement in the business negotiation meetings as an example, the importance of intercultural knowledge in the work of international secretaries has been highlighted. Power distance refers to the acceptance of the fact that people in a society are unequal in their distribution of rights. Countries with high acceptance have a clear social hierarchy and a great power distance; countries and peoples with lower acceptance are more equal and have less power distance. In general, for the board of directors in American companies, such as Boeing, when you walk into the meeting room, see where they sit and listen to the speaker's tone, and you can roughly guess who is in power or the main decision maker. However, for the board of directors in the Nordic countries, such as Sweden's IKEA, the members of the board of directors seem to sit carelessly and kick up a dust, so it is difficult to find out who is the authority figure. Modesty and equality are the connotations of Nordic culture. Upon understanding such cultural differences, the secretaries will not make mistakes or have embarrassment in arranging meeting seats and organizing meetings.

\section{Intercultural COMmunicative COMPETEnCE Cultivation Strategy OF InTERnational Secretarial} PERSONNEL

Through the current situation of intercultural communicative competence cultivation of international secretarial talents and the analysis of the importance of intercultural communicative competence in the work of international secretaries, we can see that it is urgent to optimize the cultivation strategy of intercultural communicative competence, and the focus can be reformed from the following aspects.

\section{A. Construction of Professional Textbooks}

We shall strengthen the construction of textbooks and give full play to the role of the textbooks of intercultural communicative competence in the secretary quality cultivation. It is particularly important to cultivate the high-quality and practical professional textbooks for secretarial talents. At present, the phenomenon that the professional textbooks of international secretaries are not applicable and lag behind is serious. The teaching mode of emphasis on theoretical knowledge, lack of skills training content, repetition of content and unclear expression can not only bring difficulties to teachers' teaching, but also set up obstacles for students' learning. We shall strengthen the construction of textbooks and supplement the content of teaching. We shall not only emphasize the pertinence, but also emphasize the skills and practicability. Teachers shall be organized to write new applicable textbooks, and give full play to the role of the textbooks in the secretary quality cultivation. The new textbooks shall have the following characteristics:

1) The overall idea is clear, and the hierarchical structure is multilayer; the preparation and revision of the professional textbooks should keep up with the market changes. The so-called market change, in fact, is the change of the requirements for the quality of the secretary personnel, the extension of the secretarial work area and the development of the connotation of the secretaries' professional skills. As a product, the textbooks, especially the textbooks of the application subject, should not be separated from the market, but should keep up with the market pace and strive to be innovative and meet the market demand.

2) The textbooks should be suitable for students to learn (self-study) and useful for students to improve their interest; an excellent textbook must be loved by the students with its vivid form and can help to enhance students' interest in learning. Therefore, in the construction of textbooks, we must also pay attention to enhancing students' sense of professional identity.

3) We should put emphasis on case teaching and highlight the ability cultivation. The professional secretarial textbooks should timely absorb the new ideas, new methods and new technologies of the modern secretary in intercultural communication, introduce the vivid cases of production and service enterprises, select the novel and representative themes that can reflect the forefront of secretarial career development and secretarial work, integrate the real situation and professional background of the secretaries' work into the textbooks and display it in a rich and acceptable form, so that students can conduct situation simulation exercises and experiential training, promote role 
transformation, and gain professional knowledge and practical experience in the context of learning about the relevant work background.

\section{B. Update of Professional Curriculum System}

At present, most colleges and universities have a significant lag in the courses of international secretarial courses, mainly in professional basic course modules and professional course modules. Professional basic courses include Chinese ancient literature, ancient Chinese, the history and works of contemporary Chinese literature and so on. Professional course modules include secretarial studies, document writing, office automation software application and so on. Such a curriculum system is mainly based on the curriculum model of more than a decade ago. Therefore, it is necessary to participate in intercultural courses to meet the needs of the times. The intercultural courses can also be divided into intercultural basic course modules and intercultural integrated course modules. Among them, the basic course module is compulsory, while the integrated module is elective. At the same time, in these international courses, colleges and universities should develop professional ability and quality cultivation curriculum standard with students as the center, business process as the guidance, enhancement of vocational ability as the core and work as the main teaching contents. Colleges and universities should also adopt modern information technology and integrate "teaching, learning, doing" as one to enhance students' professional ability.

\section{Expansion of the Second Classroom Teaching}

The cultivation of international secretarial talents can not ignore the role of the second classroom, especially the cultivation of intercultural communicative competence. The second classroom is a supplement to regular teaching, and it can put the knowledge gained by theoretical teaching into practice. In order to strengthen the intercultural communicative competence of secretaries, we shall try to organize some useful activities that can not be arranged in the teaching but can be completed outside the classroom, and we shall also combine these activities with the career planning and design to ensure that the intercultural communication competence is really grasped by students. Specifically, in the second classroom, the cultivation of intercultural communicative competence should include intelligent service training, initiative service training and creative service training. Intelligent service training is mainly based on learning knowledge and skills; initiative service training is mainly based on organizing and participating in activities by students themselves; creative service training is mainly based on taking part in the competition.

In the second classroom, we can make good use of secretarial professional journals, websites and competitive activity resources to extract material and information, which can be regarded as an effective measure to enrich the second classroom of secretarial professional teaching.

In terms of the secretarial professional journals, the secretarial journals have a large amount of information and cover a wide range, including not only secretarial theory study and introduction of secretarial work and art, but also professional teaching and practical teaching experience, which is highly professional and authoritative. The living daily work of some secretaries or secretarial educators published in these journals can provide good material support for case studies. Moreover, compared with the relatively boring textbook theory, the typicality and readability of these cases in the secretarial journals can arouse the enthusiasm of the students and stimulate their study and thinking, which makes students be more willing to accept and obtain the rare perceptual cognition and career interests.

In terms of the professional websites, professional website is one of the main media to carry professional knowledge and disseminate industry information. Compared with textbooks, professional websites have obvious advantages in content update frequency, information transmission speed and material richness. At present, the domestic secretarial websites are mainly organized by the secretary association (association), secretary magazines, secretary service enterprises or for-profit secretary organizations. Most of these professional websites, with a wide range of sources of information, rich content integration, timely and effective update, large communication space and wide range of radiation, include all aspects of secretarial work in all walks of life and provide a wide points for others to draw on.

In terms of the competitive activity resources, organizing students to participate in secretarial activities is an advanced form of developing classroom teaching space. This is a challenge and breakthrough for traditional classroom teaching and the "sheep-keeping" practice, which is also a bold innovation for the practical teaching of the secretary. Both the campus cultural activities and regional or national competitive competitions are good practice opportunities and exhibition platforms for secretarial professional teachers and students as well as secretarial teaching activities.

\section{Promotion of Teachers' Quality}

The role of teachers in quality cultivation is irreplaceable. The teachers' influence on the students in the course of teaching is always natural, huge and long-lasting. In fact, in recent years, most of the secretarial teachers are non-secretarial professional backgrounds, generally lacking relevant theoretical research and practical experience in public relations and secretarial work. The lack of pertinence in teaching leads to a serious phenomenon of conformism. Therefore, to improve the professional quality of students, we must first improve the professional quality of teachers, and increase the proportion of teachers with "double certificates". We shall encourage teachers to actively participate in teaching and research work, put on field practice regularly in enterprises and institutions, and actively obtain domestic and foreign relevant professional qualification certificate.

In addition, in the promotion of teacher quality, the resources of enterprises are particularly important. Applied-type 
skilled talents will eventually be employed by enterprises, so in the process of cultivating the intercultural communicative competence of secretarial talents, the first step is to understand the enterprise, including the characteristics, the current situation and the job skills requirements of the enterprise, and then based on this, the promotion of teachers' quality should be considered. At the same time, excellent talents in the enterprise can also train teachers in the field of actual practice quality and improve their quality by guest lecturers or in the form of lectures. The intensity, depth and breadth of cooperation between schools and enterprises should be continuously promoted in the improvement of teachers' quality.

\section{CONCLUSION}

In a word, with the acceleration of globalization and the rapid development of China's economy in the present, intercultural communication skills should be paid more attention in the process of secretary cultivation. However, there are still many problems in the aspect of cultivating the intercultural communicative competence of international secretaries in colleges and universities, whether it is for theoretical teaching or professional practice, which directly leads the derailment of the demand of international secretaries and the actual capacity of the market. Therefore, how to further enhance the intercultural communication competence has been an important problem faced by the professional education of international secretaries. The relevant education departments should take effective measures to cultivate high-quality and international specialized talents in the field of international secretary.

The construction of professional textbooks, the update of professional curriculum system, the expansion of the second classroom teaching as well as the promotion of teachers' quality mentioned in this paper may only be the tip of the iceberg for the innovation of intercultural communication competence cultivation of international secretaries, which calls a lot of education managers, education executives and education audiences to work hard together. Only in this way can its effect be more significant to meet the needs of society.

\section{REFERENCES}

[1] E. Jeffrey Hill, Alan J. Hawkins, Maria Ferris. (2001). Michelle Weitzman.Finding an Extra Day a week: The Positive Influence of Perceived Job Flexibility on Work and Family Life Balance. Family Relations, 5, 23-30.

[2] Grant, M. R., Keim, M. C. (2002). Faculty development in publicly support two-year colleges. Community College Journal of Research and Practice, 2, 14-22.

[3] Jim Bird. (2006). Work-life balance:Doing it right and avoiding the pitfalls. Employment Relations today, 33, 22-31.

[4] Jeffrey H.Greenhaus, Nicholas J. Beutell. (1985). Sources of conflict between work and family roles .Academy of Management. The Academy of Management Review, 10, 12-30.

[5] Joanna Hughes, Nikos Bizionelos. (2007). Work-Life balance as sources of job dissatisfaction and withdrawal attitudes: An exploratory study on the views of male workers. Personnel Review, 36, 11-17.

[6] Linda Duxbury, Christopher Higgins, Donna Coghill. (2003). Voices of Canadians: Seeking Work-Life Balance. Quebec: Human Resources Development Canada, 12-32.

[7] Summers TP, Decotiis TA, DeNisi AS. (1995). A Field study of some antecedents and consequences of felt job stress. In Rick Crandall and Pamcla L Perrewe ed. Occupational Stress: A Handbook. New Jersey: Prentice Hall, 23-89.

[8] Wallace P. (2005). Distance education for gifted students: leveraging technology to expand academic options. High Ability Studies, 6, 21-30.

Qiuping Wang was born in Sichuan, China in 1985. She received his PH.D. degree in comparative culture from Guangdong University of foreign studies, China in 2017.

She is currently a lecturer in the Faculty of Chinese Language and Culture, Guangdong University of foreign studies, Guangzhou, China. Her research interests include Western Culture and Chinese literature. 